G.P. [1] zones, but with the larger and thicker G.P. [2] zones thermal activation could never provide sufficient energy for the disruption of the zones. The mechanism of hardening in aluminium-copper alloys was discussed further by D. Dew-Hughes and W. D. Robertson (Yale University). They earried out tensile tests on single crystals of alloys which contained between 1 and 5 per cent copper and which had been aged at different temperatures and then used the results obtained to test the predictions of Orowan, Fisher Hart and Pry on the relationships between the shear stress and the particle spacing. The conclusion was reached that a modification of the Fisher Hart and Pry relationship gave agreement between the observed and ealculated results. To account fully for the effects of aging upon the critical resolved shear stress, Dew-Hughes and Robertson derived the stresses required to force dislocations through the solid solution, then to pull them through the coherent strain fields surrounding the zones and finally to disrupt the zones. The sum of these three component stresses agreed closely with the observed shear stresses.

The conclusions of Kelly and of Dew-Hughes and Robertson on the modes of dislocation precipitate interactions were supported by the results presented by G. Thomas and R. B. Nicholson (University of Cambridge). They examined in the electron microscope thin foils of suitably aged aluminium alloys and observed how the dislocations interacted with coherent, partially coherent and incoherent precipitates. Clear evidence for the passage of dislocations through coherent and partially coherent precipitates was presented. But there was little evidence for the dislocation loops forming around precipitate particles as predicted by Fisher Hart and Pry. Further results on precipitate - dislocation interaction were given by E. Smith (Associated Electrical Industries, Aldermaston), who deseribed the effects of hydride precipitates upon the plastic deformation of titanium and showed how the reversible twinning found in pure titanium was hindered by the hydride precipitates. Under conditions of rapid loading cracks developed from the interface between the hydride and the hindered twin.

The generation of dislocations at incoherent interfaces was discussed by J. W. Mitchell and A. S. Parasnis (University of Bristol). They showed how, in a dispersion of glass spheres in silver chloride, the stresses developed at interfaces due to differences in thermal contraction of the two phases could lead to the formation of dislocations by a process of prismatic punching. Optical micrographs were shown of the dislocation loops and their spatial distribution within the silver chloride matrix. Another function of interfaces, as a source of vacancies, was demonstrated by R. S. Barnes (Atomic Energy Research Establishment, Harwell) and Prof. A. H. Cottrell (University of Cambridge), who had investigated the effects associated with the annealing of radiation damage in copper produced by bombardment with $\alpha$-particles. They found small bubbles were produced on anneal. ing and reasoned that these were formed by the diffusion and aggregation of vacancies from either the nearest free surface or internal surfaces such as large-angle grain boundaries; convincing proof that twin interfaces did not act as sources for vacancies was produced. The influence of curvature on the energy of incoherent interfaces was illustrated by a film presented by G. Thomas and M. J. Whelan (University of Cambridge). Thin foils of an aluminium -4 per cent copper alloy were aged at temperatures between $350^{\circ}$ and $450^{\circ} \mathrm{C}$. on a heating stage in the electron microscope while the structural changes as observed on the fluorescent screen of the microscope were recorded with a cine camera. The nucleation and growth of the $\theta$ phase was elearly revealed together with the subsequent growth of the larger particles at the expense of the smaller ones.

From the conference it appeared that at the present stage of development the physicists and metallurgists had more to offer than the physical chemists towards our understanding of interfacial phenomena. The advances made since the introduction of electron diffraction tecluniques for the study of surfaces have been very great, but with the advent of the electron microscope into this field of study a much more detailed investigation of surface morphology has become possible. The explanation of why diffraction patterns could be obtained from deposits of less than one atom mean thickness has now been found, but it is still difficult to account for the preferential formation of epitaxial nuclei at lattice defects. Perhaps it is here that the physical chemists can be of help.

\title{
THE COLOMBO PLAN
}

\section{ANNUAL REPORT}

\begin{abstract}
$\mathrm{T}$ HE seventh annual report of the Consultative Committee for the Colombo Plan for Co-operative Economic Development in. South and South-East Asia, which by agreement at the Singapore meeting of the Committee in October 1955 has been extended from July 1957 to June 30,1961 , is the last to appear before the future of the Plan is again considered at its 1959 meeting in Indonesia. The present report*, which covers the year 1957-58, records continuing increase in industrial production in the area as a whole, but in India the rate of expansion dropped from 8 per cent in $1956-57$ to 1.5 per cent, which, however, accounted for most of the 13 per cent increase in output of electric power. Since 1950

- The Colombo Plan for Co-operative Economic Development in South and South-East Asia-Seventh Annual Report of the Con(Cmnd. 610.) (London: H.M. Stationery Office, 1958.) 8s. net.
\end{abstract}

training has been given to more than 15,500 trainees from countries in the area, and the services of nearly 8,000 experts provided by members of the Colombo Plan and by agencies of the United Nations. During 1957 expenditure on technical assistance under the Colombo Plan Technical Co-operation Scheme in. creased to about $£ 3$ million, reaching a total of $£ 9.78$ million since 1950 , and during the first six months of 1958 it reached 3.9 million dollars.

Almost half of this expenditure has been for the provision of study and training courses, about a quarter for the supply of experts and the remainder on technical equipment. By the end of June 1958 expenditure on technical equipment reached a total of $£ 2.35$ million, and the number of scholarships and training awards granted by member countries totalled 6,952 , an increase of 1,330 on the previous year. 
There were then 2,091 trainees taking courses in member countries. During the year there were 221 technical experts in the field compared with 207 in the previous year, making a total of 1,002 since the Plan began. The number of experts supplied in medical and health fields dropped sharply, but the number of engineering experts increased, and the number of those in food, agriculture and forestry and in transport and communications continued to increase.

Outside the Technical Co-operation Scheme, the United States, which has already provided, since the inception of the Plan, almost 4,000 million dollars in economic and technical assistance to Colombo Plan countries, continued to provide large-scale technical assistance. About 1,500 trainees were received in the United States and 543 trainees undertook instructional courses with United States assistance in the Colombo Plan area, while on July 1, 1958, about 2,000 United States technicians were on duty in Colombo Plan countries. Under the Mutual Security Programme and the President's Fund for Asian Economic Development, 408 million dollars were made available to Colombo Plan countries during the year, and finance was provided for a Radioisotope Centre in Burma, including arrangements to train Burmese in nuclear techniques in the United States. Laboratory equipment was provided for a course in nuclear physics at the University of the Philippines, and scientists from the Philippines and Thailand are being trained in the United States.

During the year, fewer new Colombo Plan scholarships and training awards were granted, partly because of the pressure on existing training institutions but partly also because of the marked increase in the number of long-term awards. The establish. ment and development of training facilities within the area accelerated and 20 per cent of the training awards under the Technical Co-operation Scheme are now provided within the area. Looking to the future, the report again stresses the need to ensure that technical and managerial skills are developed at a rate sufficient to permit the effective use of capital and other available resources. The technical ability of the population must keep pace with the expansion of development and it is now urged that the lessdeveloped countries give greater attention to the development of human skills required for the effective and appropriate utilization of resources. Finally, stress is laid both on the value of co-operation and of the more rapid development of technical training facilities within the area.

\section{BEAR ISLAND COD}

$\mathrm{D}$ URING the summer, shoals of cod, consisting mainly of immature individuals, move into feeding grounds off Bear Island near Spitsbergen. These concentrations form an important fishery resource, and for the past ten years, part of the work of the Fisheries Laboratory, Lowestoft, has been to trace the migrations that lead to this shoaling behaviour.

In doing this work*, Mr. G. C. Trout has been greatly helped by discovering that these cod have two main kinds of otoliths, which he calls split-zone and opaque-zone types. Both kinds are found in roughly equal proportions on the more southerly grounds, but with increasing distance from Bear Island the two tend to become segregated. This and other evidence suggested that the shoals advancing on Bear Island separate into two groups, one moving north-eastwards in the direction of Hope Island and the other northwards to Spitsbergen. Tagging experiments carried out during 1951 and 1952 were in keeping with this hypothesis and showed that in

* The Bear Island Cod: Migrations and Movements. By G. C. Trout. Fishery Investigations, Series II, Vol. 21, No. 6. Pp. 51. late autumn the fish returned to winter quarters in the Bear Island area.

Trout suggests that these facts and others are consistent with the general idea that the annual migratory cycle of the Barents Sea cod populations is closely linked with the movements of the water masses. During their summer migrations the feeding cod are partly pelagic in habit (due to daily vertical migrations in response to light conditions) and may thus drift northwards in the West Spitsbergen eurrent or in a branch of the North Atlantic drift. The return migration in winter is against the current and takes place along the bottom in the absence of light (and the lack of daily vertical movement in the fish). The distribution of the cod is thus seen to be ". . . the resultant of interaction of changing behaviour with the cycle of movement of the water masses in which the cod are found".

This would seem to be a useful working hypothesis. Perhaps it will prove to be partly right, but the fact that it can be posed at all is a measure of the work being undertaken by the Fisheries Laboratory at Lowestoft.
N. B. Marshatit

\section{PROGRESS IN BRITISH FORESTRY}

$\mathrm{T}$ HE thirty-eighth annual report of the Forestry Commissioners for the year ending September 30 , $1957 *$, reviews both the record of work accomplished in Britain and the national situation in relation to policy and programmes adopted by the Government. The record as a whole must be accepted as quite satisfactory, with encouraging features indicating that some at least of long-standing difficulties are being overcome, even if others, such as that of acquiring land for afforestation, have definitely held

* Thirty-eighth Annual Report of the Forestry Commissioners for the year ended 30 th September. 1957 . Pp. $90+4$ plates. (London :
H.M. Stationery Office, 1958.) 58. 6d. net. up progress in planting work. Criticism has been made in the past that not enough was being done to get the productivity of the privately owned woodlandsstill the greater proportion over the country as a whole and still far from having recovered from the onslaught of two world wars-restored and brought, up to the levels possible with skilled management. The rate of planting by private owners has nearly doubled in the past five years and has increased by as much as 4,500 acres in 1956-57, compensating for a drop of the same order in the State's own total. This increase is significant as revealing a changed situation which has been widely discussed, both in 